\title{
Palm dermatoglyphs and interleukin-4 receptor polymorphisms in asthma
}

\author{
LIXIN SUN ${ }^{1 *}$, WEILIN XUE ${ }^{2 *}, \mathrm{JUN} \mathrm{LI}^{3 *}$, ZHAOSHAN ZHOU ${ }^{2}$ and WEI HAN ${ }^{3}$ \\ ${ }^{1}$ Department of Anesthesiology, Qingdao Municipal Hospital, Qingdao, Shandong 266071; \\ ${ }^{2}$ Department of Respiratory Medicine, Qingdao Haici Hospital, Qingdao, Shandong 266033; \\ ${ }^{3}$ Department of Respiratory Medicine, Qingdao Municipal Hospital, Qingdao, Shandong 266071, P.R. China
}

Received August 23, 2016; Accepted October 13, 2016

DOI: $10.3892 /$ br.2016.803

\begin{abstract}
Single nucleotide polymorphisms (SNPs) in the interleukin-4 receptor (IL-4R) gene have been identified as having a close association with asthma severity in different populations. In our previous studies, a close association between asthma and a distinctive palm dermatoglyphic pattern was observed; however, the clinical implication and underlying genetic mechanisms of this particular palm pattern have not been clarified. Whether this particular palm pattern is associated with asthma severity and IL-4R SNPs was assessed in the present study. A case cohort study was conducted in 400 patients with allergic asthma and in 200 healthy controls. DNA was extracted from peripheral blood leukocytes for analysis of 11 IL-4R SNPs associated with asthma via polymerase chain reaction. There are two SNPs, rs1805012 and rs3024608, which are associated with asthma (rs1805012, dominant model; $\mathrm{P}=0.03$ and rs3024608, codominant model; $\mathrm{P}=0.029)$, and two SNPs, rs1805010 and rs3024608, which are associated with the positive palm pattern (rs1805010, log-additive model; $\mathrm{P}=0.031$ and rs3024608, codominant model; $\mathrm{P}=0.016)$. The SNP of
\end{abstract}

Correspondence to: Dr Wei Han, Department of Respiratory Medicine, Qingdao Municipal Hospital, 5 Donghai Middle Road, Qingdao, Shandong 266071, P.R. China

E-mail: sallyhan1@163.com

Dr Zhaoshan Zhou, Department of Respiratory Medicine, Qingdao Haici Hospital, 4 Renmin Road, Qingdao, Shandong 266033, P.R. China

E-mail: slyyicqd@163.com

*Contributed equally

Abbreviations: SNP, single nucleotide polymorphisms; IL-4, interleukin-4; IL-13, interleukin-13; IL-4R, interleukin-4 receptor; GINA, Global Initiative for Asthma; ADAM33, a disintegrin and metalloprotein-33; PCR, polymerase chain reaction

Key words: asthma, interleukin, polymorphisms, palm, dermatoglyphics rs3024608 is associated with asthma and the positive palm pattern. Thus, genetic variation in IL-4R may be associated with the development of asthma and the distinctive palm pattern; however, further investigations are required to identify the connection between asthma and palm dermatoglyphic patterns.

\section{Introduction}

Since last century, the prevalence of asthma has increased worldwide, which has resulted in substantial morbidity and healthcare costs (1). Patients with different phenotypes have different outcomes and prognoses. The most effective treatment strategy to effectively control asthma, as suggested by the Global Initiative for Asthma (GINA), is to implement personalized treatment according to the different phenotypes of asthma. However, it is difficult to correctly and rapidly identify the phenotype using simple clinical features, without complicated or invasive examinations.

Genetic susceptibility is critical in the development of asthma; therefore, it is often used to identify the phenotypes of asthma. Interleukin-4 receptor (IL-4R) is important in regulating $\mathrm{T}$ helper (Th) 2 cell development and immunoglobulin $\mathrm{E}$ (IgE) production via its response to IL-4 or IL-13 (2). The loci of IL-4R, located on genomic region 16p12, are linked to asthma phenotypes with increased airway mast cells and IgE (+) cells. Numerous single nucleotide polymorphisms (SNPs) in IL-4R gene have been associated with a phenotype of severe asthma $(3,4)$. However, sequencing the IL-4R gene for every patient is not considered a feasible method of differentiating the phenotypes of asthma.

In the past two decades, the value of palm dermatoglyphic or fingerprint patterns has been described in the detection of bronchial asthma by different studies; however, the underlying mechanisms have not been clarified (5-8). In our previous study, a distinctive palm pattern was identified, which was characterized by deep grids in the thenar area that facilitated the diagnosis of asthma, with a close association to two a disintegrin and metalloprotein-33 (ADAM33) gene polymorphisms (9). The palm pattern appears to be a potential biomarker for endotypes of asthma, although the association between distinctive palm patterns and other SNPs associated with asthma have yet to be investigated. 
Thus, in the present study, 11 SNPs of the IL-4R gene were analyzed in a population of East Chinese Han adults to clarify the link between a particular palm pattern and IL-4R gene polymorphisms.

\section{Materials and methods}

Subjects. A total of 400 asthma patients were recruited from the pulmonary clinics of two teaching hospitals, Qingdao Municipal Hospital (Qingdao, China) and Qingdao Haici Hospital (Qingdao, China) from January 2011 to January 2012 successively. Asthma was diagnosed and evaluated based on symptoms and on spirometry assessments by the criteria of the Global Initiative for Asthma (version: 2010 update) (10). Two-hundred healthy adults were recruited successively from the Health check-up centers of Qingdao Municipal Hospital and Qingdao Haici Hospital to serve as healthy controls. All control subjects were asymptomatic for asthma and devoid of any atopic or pulmonary diseases. Pregnant or lactating female subjects were excluded. The age range for all of the study subjects was 18-70 years old. Smoking status and education history data were collected for all subjects. The study was performed in accordance with the Helsinki Declaration and approved by the Ethics Committee of Qingdao Municipal Hospital and Qingdao Haici Hospital. In addition, all subjects provided written informed consent prior to the study.

Dermatoglyphic palm patterns. The palms of each subject were observed, after washing clean with soap and water, by two researchers under natural light. The palm patterns were determined by the dermatoglyphic variables in the thenar area, including number and shape of the ridges, as described in our previous study (9). A positive palm pattern typically exhibited an increased ridge count $(\geq 10)$ and deep grid patterns in the thenar area, while a negative palm pattern demonstrated normal ridge count $(<10)$ and light grid patterns in the thenar area. All subjects were sub-categorized into two groups; a positive palm pattern group and a negative palm pattern group according to the above standard.

Polymorphism genotyping. Whole blood $(10 \mathrm{ml})$ was taken in lithium heparin-coated test tubes from each subject and immediately centrifuged at 1,600 x g. Buffy coat (peripheral white cells) was separated and stored at $-70^{\circ} \mathrm{C}$ on the day of enrollment by a nurse. Genomic DNA was isolated from the peripheral blood leukocytes using a DNA extraction kit (Tiangen Biotech Co., Ltd., Beijing, China). The DNA was genotyped for the SNPs of the IL-4R gene at the Center for Human Genetics Research, Shanghai Genesky Bio-Tech Co., Ltd. (Shangai, China). Three SNPs of the IL-4R gene, rs1805010, rs1805012 and rs1801275, were selected according to the published literatures regarding SNP associations with asthma $(11,12)$. Eight tag SNPs, rs3024608, rs1110470, rs3024685, rs3024619, rs2057768, rs3024585, rs12925861, and rs3024613, were then selected according to the frequency information for Chinese populations from two public databases the International HapMap Project (http://www.hapmap. org/) and the NCBI database (http://www.ncbi.nlm.nih.gov/). The PCR primers were designed by the authors and are presented in Table I.
Polymerase chain reaction (PCR) amplification of the corresponding genomic region surrounding each SNP locus was performed in a Takara PCR thermal cycler (Takara TP600; Takara Biotechnology Co., Ltd., Dalian, China). The reaction was performed in a final volume of $10 \mu \mathrm{l}$, including $3.0 \mathrm{mM} \mathrm{Mg}{ }^{2+}, 0.3 \mathrm{mM}$ dNTP, 1 unit HotStarTaq polymerase (Qiagen Inc., Valencia, CA, USA), $1 \mu$ l of each primer, and $1 \mu \mathrm{l}(10 \mathrm{ng})$ of genomic DNA. The cycling conditions were as follows: $1 \mathrm{Cycle}$ at $95^{\circ} \mathrm{C}$ for $2 \mathrm{~min}, 11$ cycles at $94^{\circ} \mathrm{C}$ for $20 \mathrm{sec}$, $65-0.5^{\circ} \mathrm{C}$ for $40 \mathrm{sec}$ and $72^{\circ} \mathrm{C}$ for $1.5 \mathrm{~min}$, and 24 cycles at $94^{\circ} \mathrm{C}$ for $20 \mathrm{sec}, 59^{\circ} \mathrm{C}$ for $30 \mathrm{sec}$ and $72^{\circ} \mathrm{C}$ for $1.5 \mathrm{~min}$, and a final extension at $72^{\circ} \mathrm{C}$ for $2 \mathrm{~min}$. The PCR products were purified using a PCR purification kit containing lunit Shrimp Alkaline Phosphatase (SAP) and 1 unit Exonuclease I (Qiagen GmbH, Hilden, Germany) and were used as DNA templates for the cycle sequencing. Direct DNA sequencing was performed using $5 \mu \mathrm{l}$ SNaPshot Multiplex kit (Applied Biosystems; Thermo Fisher Scientific, Inc., Waltham, MA, USA) in 10- $\mu$ l volumes containing $2 \mu \mathrm{l}$ primer and $2 \mu \mathrm{l}$ DNA template, and were subjected to 1 cycle at $96^{\circ} \mathrm{C}$ for $1 \mathrm{~min}, 28$ cycles of denaturation at $96^{\circ} \mathrm{C}$ for $10 \mathrm{sec}$, annealing at $52^{\circ} \mathrm{C}$ for $5 \mathrm{sec}$, and extension at $60^{\circ} \mathrm{C}$ for $30 \mathrm{sec}$. Sequencing products were purified using 1 unit SAP at $37^{\circ} \mathrm{C}$ for $1 \mathrm{~h}$ and annealing at $75^{\circ} \mathrm{C}$ for $15 \mathrm{~min}$. All SNPs were detected with an ABI 3130xl, and the data were analyzed with GeneMapper 4.0 (Applied Biosystems; Thermo Fisher Scientific, Inc.). The association analysis between a single SNP and phenotype were conducted under five different genetic models (inheritance patterns) as follows: Codominant, dominant, recessive, overdominant and log-additive.

Statistical analysis. The differences in age, gender, body mass index (BMI), smoking status and education history between patients and control subjects were compared using the $\chi^{2}$ test or a t-test accordingly. The correlation between palm patterns and asthma severity was evaluated by Spearman analysis. The odds ratios (ORs) and 95\% confidence interval (CI) of asthma risk of individuals with various genetic polymorphisms were calculated using logistic regression analysis adjusting for differences in gender. Hardy-Weinberg equilibrium and linkage disequilibrium was estimated using SNPAnalyzer version 2.0 (Istech Corp., Korea; http://istech21.com/). Statistical analyses were conducted using the SPSS for Windows version 17.5, statistical package (SPSS, Inc, Chicago, IL, USA) and $\mathrm{P}<0.05$ was considered to indicate a statistically significant difference.

\section{Results}

Demographics. The demographics of the asthma group and the control group are presented in Table II. No significant differences were identified between the age, gender, BMI, smoking status, and education history of the asthma and control groups (all $\mathrm{P}>0.05$ ).

Polymorphisms with asthma. All genotype frequencies were consistent with Hardy-Weinberg equilibrium $(\mathrm{P}>0.05)$. The genotype distributions of all 11 IL-4R SNPs in the asthma and control groups are listed in Table III. There are two SNPs, rs1805012 and rs3024608, which are associated with asthma in different models as follows: rs1805012, dominant model $(\mathrm{P}=0.03)$ and rs3024608, codominant model $(\mathrm{P}=0.029)$. 
Table I. Oligonucleotide primers used for resequencing interleukin-4 receptor.

Oligonucleotide primers

\begin{tabular}{lll} 
SNP & \multicolumn{1}{c}{ Forward } & \multicolumn{1}{c}{ Reverse } \\
\cline { 2 - 3 } rs1805010 & CAGCCAGCCTACAGGTGACCA & CTGACCACGTCATCCATGAGCA \\
rs1805012 & GGAGAGGAGAATGGGGGCTTTT & ACTTGGCTCCAGGTGGAGAG \\
rs1801275 & AGATCCTCCGCCGAAATGTCCT & ACCCTGCTCCACCGCATGTA \\
rs3024608 & CAGCCAGGAAGTGGTAGTAGGGACT & TCGTTAGCTGACCCCACCATGT \\
rs1110470 & AGCCTTCACTGGCTCCCCACT & GGAGAAGGACTGGCTGGGATG \\
rs3024685 & ATGCCCTAACCTCCCAGGAATG & TACCCCAGCTCCCTCTCCTTTG \\
rs3024619 & AGAACTACAGAGGAAACTAATTGTATTGAAATG & TCCTGTCCCCAGCAAAACAAAA \\
rs2057768 & CCCTAGATGGGGGAACAGAGGTT & GCATTGTTCTCGGGTGCAAGAG \\
rs3024585 & CCACCTTCAGAGTCCAAAGATATGTTATTT & CATGAGGGAAGAGCCTGCCTAAA \\
rs12925861 & AAGCTGCCCACTGCTTAGAGGA & TCATGGGTCTTAAATCCAGCACTCA \\
rs3024613 & CAGACACTTCCCCTGGCTGAGT & CAGGGAGGGAAACCACCTACAA
\end{tabular}

SNP, single nucleotide polymorphism.

Table II. Demographics of asthma patients and healthy control subjects (presented as means \pm standard deviation).

\begin{tabular}{|c|c|c|c|c|c|}
\hline Variable & Asthma $(n=400)$ & Control $(n=200)$ & $\mathrm{t}$ & $\chi^{2}$ & P-value \\
\hline Age, years & $40.11 \pm 14.54$ & $45.42 \pm 16.28$ & 0.35 & - & $>0.05$ \\
\hline Body mass index, $\mathrm{kg} / \mathrm{m}^{2}$ & $24.78 \pm 3.22$ & $24.51 \pm 3.40$ & 0.09 & - & $>0.05$ \\
\hline Gender & & & - & 1.98 & $>0.05$ \\
\hline Male & 172 & 74 & & & \\
\hline Female & 228 & 126 & & & \\
\hline Smoking & & & - & 0.50 & $>0.05$ \\
\hline Smoker ${ }^{\mathrm{a}}$ & 115 & 52 & & & \\
\hline Non-smoker & 285 & 148 & & & \\
\hline Education, years & $15.24 \pm 8.13$ & $15.89 \pm 8.81$ & 0.08 & - & $>0.05$ \\
\hline
\end{tabular}

${ }^{\mathrm{a} C}$ Current and previous smokers.

Table III. Genotype of interleukin-4 receptor SNPs in the asthma and control groups (adjusted for gender and age).

\begin{tabular}{lcccc}
\hline SNP & Genotype & Control, $\mathrm{n}(\%)$ & Asthma, $(\%)$ & Odds ratio (95\% CI) \\
\hline rs2057768 & T/T & $63(31.50$ & $115(28.97)$ & 1 \\
& $\mathrm{C} / \mathrm{T}$ & $93(46.50)$ & $195(49.11)$ & $1.06(0.68-1.65)$ \\
C/C & $44(22.00)$ & $87(21.91)$ & $1.07(0.62-1.84)$ \\
rs1110470 & G/G & $85(42.50)$ & $161(40.25)$ & 1 \\
& G/A & $93(46.50)$ & $183(45.75)$ & $0.97(0.65-1.47)$ \\
A/A & $22(11.00)$ & $56(14.00)$ & $1.34(0.71-2.50)$ \\
rs12925861 & A/A & $58(29.00)$ & $111(27.80)$ & 1 \\
& A/T & $95(47.50)$ & $201(50.20)$ & $1.03(0.66-1.62)$ \\
rs1805010 & T/T & $47(23.50)$ & $88(22,00)$ & $0.95(0.55-1.62)$ \\
& G/G & $54(27.14)$ & $112(28.14)$ & 1 \\
G/A & $99(49.75)$ & $201(50.50)$ & $0.88(0.56-1.38)$ \\
& A/A & $46(23.12)$ & $85(21.36)$ & $0.82(0.48-1.41)$ \\
& A/A & $88(44.22)$ & $173(43.57)$ & 1
\end{tabular}


Table III. Continued.

\begin{tabular}{|c|c|c|c|c|c|}
\hline SNP & Genotype & Control, n (\%)+ & Asthma, n (\%) & Odds ratio $(95 \% \mathrm{CI})$ & P-value \\
\hline \multirow[t]{3}{*}{ rs3024608 } & $\mathrm{C} / \mathrm{C}$ & $161(80.50)$ & $340(85.56)$ & 1 & 0.03 \\
\hline & $\mathrm{C} / \mathrm{G}$ & $39(19.50)$ & $53(13.35)$ & $0.56(0.33-0.94)$ & \\
\hline & $\mathrm{G} / \mathrm{G}$ & $0(0)$ & $4(1.01)$ & $\mathrm{NA}(0.00-\mathrm{NA})$ & \\
\hline \multirow[t]{3}{*}{ rs3024613 } & $\mathrm{C} / \mathrm{C}$ & $56(28.28)$ & $99(25.00)$ & 1 & 0.39 \\
\hline & $\mathrm{C} / \mathrm{T}$ & 95 (47.98) & $208(52.53)$ & $1.37(0.86-2.18)$ & \\
\hline & $\mathrm{T} / \mathrm{T}$ & $47(23.73)$ & $89(22.47)$ & 1.15 (0.67-1.99) & \\
\hline \multirow[t]{3}{*}{ rs3024619 } & $\mathrm{G} / \mathrm{G}$ & $68(34.00)$ & $122(30.73)$ & 1 & 0.51 \\
\hline & $\mathrm{G} / \mathrm{A}$ & $95(47.50)$ & $205(51.64)$ & $1.26(0.82-1.95)$ & \\
\hline & $\mathrm{A} / \mathrm{A}$ & $37(18.50)$ & $70(17.63)$ & $1.02(0.58-1.79)$ & \\
\hline \multirow[t]{3}{*}{ rs1805012 } & $\mathrm{T} / \mathrm{T}$ & $169(84.50)$ & $361(90.93)$ & 1 & 0.03 \\
\hline & $\mathrm{C} / \mathrm{T}$ & $31(15.50)$ & $35(8.82)$ & $0.50(0.27-0.90)$ & \\
\hline & $\mathrm{C} / \mathrm{C}$ & $0(0)$ & $1(0.25)$ & NA (0.00-NA) & \\
\hline \multirow[t]{3}{*}{ rs1801275 } & $\mathrm{A} / \mathrm{A}$ & $141(70.50)$ & $281(70.78)$ & 1 & 0.47 \\
\hline & $\mathrm{G} / \mathrm{A}$ & $51(25.50)$ & $108(27.20)$ & $0.97(0.62-1.51)$ & \\
\hline & $\mathrm{G} / \mathrm{G}$ & $8(4.00)$ & $8(2.05)$ & $0.48(0.15-1.53)$ & \\
\hline \multirow[t]{3}{*}{ rs3024685 } & $\mathrm{C} / \mathrm{C}$ & $67(33.50)$ & $133(33.25)$ & 1 & 0.87 \\
\hline & $\mathrm{C} / \mathrm{T}$ & $97(48.50)$ & $194(48.50)$ & $0.90(0.59-1.38)$ & \\
\hline & $\mathrm{T} / \mathrm{T}$ & $36(18.00)$ & $73(18.25)$ & $0.90(0.51-1.58)$ & \\
\hline
\end{tabular}

SNP, single nucleotide polymorphism; CI, confidence interval.

Table IV. Genotype of interleukin-4 receptor SNPs in the negative and positive palm pattern groups (adjusted for gender and age).

\begin{tabular}{|c|c|c|c|c|c|}
\hline SNP & Genotype & Negative palm, n (\%) & Positive palm, n (\%) & Odds ratio $(95 \% \mathrm{CI})$ & P-value \\
\hline \multirow[t]{3}{*}{ rs1805010 } & $\mathrm{G} / \mathrm{G}$ & $81(25.55)$ & $85(30.4)$ & 1 & \multirow[t]{3}{*}{0.031} \\
\hline & $\mathrm{G} / \mathrm{A}$ & $157(49.53)$ & $143(51.1)$ & $0.79(0.52-1.19)$ & \\
\hline & $\mathrm{A} / \mathrm{A}$ & $79(24.92)$ & $52(18.6)$ & $0.58(0.35-0.95)$ & \\
\hline \multirow[t]{3}{*}{ rs1805012 } & $\mathrm{T} / \mathrm{T}$ & $282(88.68)$ & $248(88.9)$ & 1 & \multirow[t]{3}{*}{0.47} \\
\hline & $\mathrm{C} / \mathrm{T}$ & $36(11.32)$ & $30(10.8)$ & $1.10(0.62-1.94)$ & \\
\hline & $\mathrm{C} / \mathrm{C}$ & $0(0)$ & $1(0.4)$ & $\mathrm{NA}(0.00-\mathrm{NA})$ & \\
\hline \multirow[t]{3}{*}{ rs 1801275} & $\mathrm{~A} / \mathrm{A}$ & $228(71.69)$ & $194(69.53)$ & 1 & \multirow[t]{3}{*}{0.42} \\
\hline & $\mathrm{G} / \mathrm{A}$ & $83(26.10)$ & $76(27.24)$ & $1.04(0.70-1.55)$ & \\
\hline & $\mathrm{G} / \mathrm{G}$ & $7(2.21)$ & $9(3.23)$ & $2.15(0.67-6.84)$ & \\
\hline \multirow[t]{3}{*}{ rs3024608 } & $\mathrm{C} / \mathrm{C}$ & $264(83.02)$ & $237(84.95)$ & 1 & \multirow[t]{3}{*}{0.02} \\
\hline & $\mathrm{C} / \mathrm{G}$ & $54(16.93)$ & $38(13.62)$ & $0.73(0.44-1.19)$ & \\
\hline & $\mathrm{G} / \mathrm{G}$ & $0(0)$ & $4(1.43)$ & NA (0.00-NA) & \\
\hline \multirow[t]{3}{*}{ rs1110470 } & $\mathrm{G} / \mathrm{G}$ & $121(37.93)$ & $125(44.48)$ & 1 & \multirow[t]{3}{*}{0.2} \\
\hline & $\mathrm{G} / \mathrm{A}$ & $155(48.58)$ & $121(43.06)$ & $0.71(0.49-1.04)$ & \\
\hline & $\mathrm{A} / \mathrm{A}$ & $43(13.48)$ & $35(12.45)$ & $0.79(0.46-1.38)$ & \\
\hline \multirow[t]{3}{*}{ rs3024685 } & $\mathrm{C} / \mathrm{C}$ & $106(33.22)$ & $94(33.45)$ & 1 & \multirow[t]{3}{*}{0.96} \\
\hline & $\mathrm{C} / \mathrm{T}$ & $154(48.27)$ & $137(48.75)$ & $0.97(0.66-1.44)$ & \\
\hline & $\mathrm{T} / \mathrm{T}$ & $59(18.50)$ & $50(17.79)$ & $0.93(0.56-1.54)$ & \\
\hline \multirow[t]{3}{*}{ rs3024619 } & $\mathrm{G} / \mathrm{G}$ & $105(33.02)$ & $85(30.46)$ & 1 & \multirow[t]{3}{*}{0.49} \\
\hline & $\mathrm{G} / \mathrm{A}$ & $161(50.63)$ & $139(49.82)$ & $1.10(0.74-1.64)$ & \\
\hline & $\mathrm{A} / \mathrm{A}$ & $52(16.45)$ & $55(19.71)$ & $1.36(0.82-2.28)$ & \\
\hline \multirow[t]{3}{*}{ rs2057768 } & $\mathrm{T} / \mathrm{T}$ & 89 (27.99) & $89(31.90)$ & 1 & \multirow[t]{3}{*}{0.44} \\
\hline & $\mathrm{C} / \mathrm{T}$ & $153(48.11)$ & $135(48.38)$ & $0.85(0.57-1.28)$ & \\
\hline & $\mathrm{C} / \mathrm{C}$ & $76(23.90)$ & 55 (19.71) & $0.73(0.44-1.19)$ & \\
\hline
\end{tabular}


Table IV. Continued.

\begin{tabular}{|c|c|c|c|c|c|}
\hline SNP & Genotype & Negative palm, n (\%) & Positive palm, n (\%) & Odds ratio $(95 \% \mathrm{CI})$ & P-value \\
\hline \multirow[t]{3}{*}{ rs3024585 } & $\mathrm{A} / \mathrm{A}$ & $131(41.19)$ & $130(46.59)$ & 1 & 0.19 \\
\hline & $\mathrm{G} / \mathrm{A}$ & $150(47.17)$ & $121(43.37)$ & $0.74(0.51-1.08)$ & \\
\hline & $\mathrm{G} / \mathrm{G}$ & $37(11.64)$ & $28(10.04)$ & $0.66(0.37-1.19)$ & \\
\hline \multirow[t]{3}{*}{ rs12925861 } & $\mathrm{A} / \mathrm{A}$ & $84(26.33)$ & $85(30.25)$ & 1 & 0.14 \\
\hline & $\mathrm{A} / \mathrm{T}$ & $153(47.96)$ & $143(50.89)$ & $0.88(0.58-1.33)$ & \\
\hline & $\mathrm{T} / \mathrm{T}$ & $82(25.71)$ & $53(18.86)$ & $0.62(0.37-1.01)$ & \\
\hline \multirow[t]{3}{*}{ rs3024613 } & $\mathrm{C} / \mathrm{C}$ & $78(24.68)$ & $77(27.70)$ & 1 & 0.65 \\
\hline & $\mathrm{C} / \mathrm{T}$ & $163(51.58)$ & $140(50.36)$ & $0.86(0.56-1.31)$ & \\
\hline & $\mathrm{T} / \mathrm{T}$ & $75(23.73)$ & $61(21.44)$ & $0.80(0.48-1.32)$ & \\
\hline
\end{tabular}

SNP, single nucleotide polymorphism; CI, confidence interval.

Polymorphisms with palm patterns. The genotype distribution of all 11 IL-4R SNPs in the negative and positive palm groups are presented in Table IV. Two SNPs, rs1805010 and rs3024608, were associated with the positive palm pattern in different models as follows: rs1805010, log-additive model $(\mathrm{P}=0.031)$ and $\mathrm{rs3024608}$, codominant model $(\mathrm{P}=0.016)$. Notably, rs3024608 is associated with asthma and the positive palm pattern. The rs1805010, rs1805012 and rs3024608 with different genotypes are presented in Fig. 1.

\section{Discussion}

In the present study, gene segments of 11 SNPs of the IL-4R gene were amplified to identify the genetic basis of the association between a distinctive palm dermatoglyphic pattern and asthma in a Chinese population.

As the results of SNP studies are not always consistent in different populations, the present study evaluated the role of SNPs of IL-4R in asthma development in the Chinese population. Although three SNPs, rs1801275 (-1902G/A), rs1805012 (1291T/C) and rs1805010 (-223G/A) demonstrated associations with asthma in previous studies (11-13), only rs1805012 exhibited an association with asthma (dominant model; $\mathrm{P}=0.03$ ) in the current study. To further investigate the effect of IL-4R SNPs in asthma, eight tag SNPs of the IL-4R region were investigated for an association with asthma, to the best of our knowledge, for the first time. Of these SNPs, two were associated with asthma in a different model: rs1805010, log-additive model $(\mathrm{P}=0.031)$ and $\mathrm{rs} 3024608$, codominant model $(\mathrm{P}=0.016)$. Thus, polymorphisms of the IL-4R gene may be the genetic basis of asthma in this particular population.

Dermatoglyphs are formed in the 10th to 17 th weeks of the embryological phase, when the neurologic and immunity systems are developing. Generally dermatoglyphs remain unchanged throughout an individual's life, except in cases of serious injuries that scar the dermis. Thus, a series of studies have identified the association of dermatoglyphic patterns with certain congenital defects or gene-associated diseases, such as Down's syndrome (14-17). However, few practical associations have been recognized in humans. Palm patterns are affected by many complex factors, for example age-associated changes,

\section{A rs1805010}

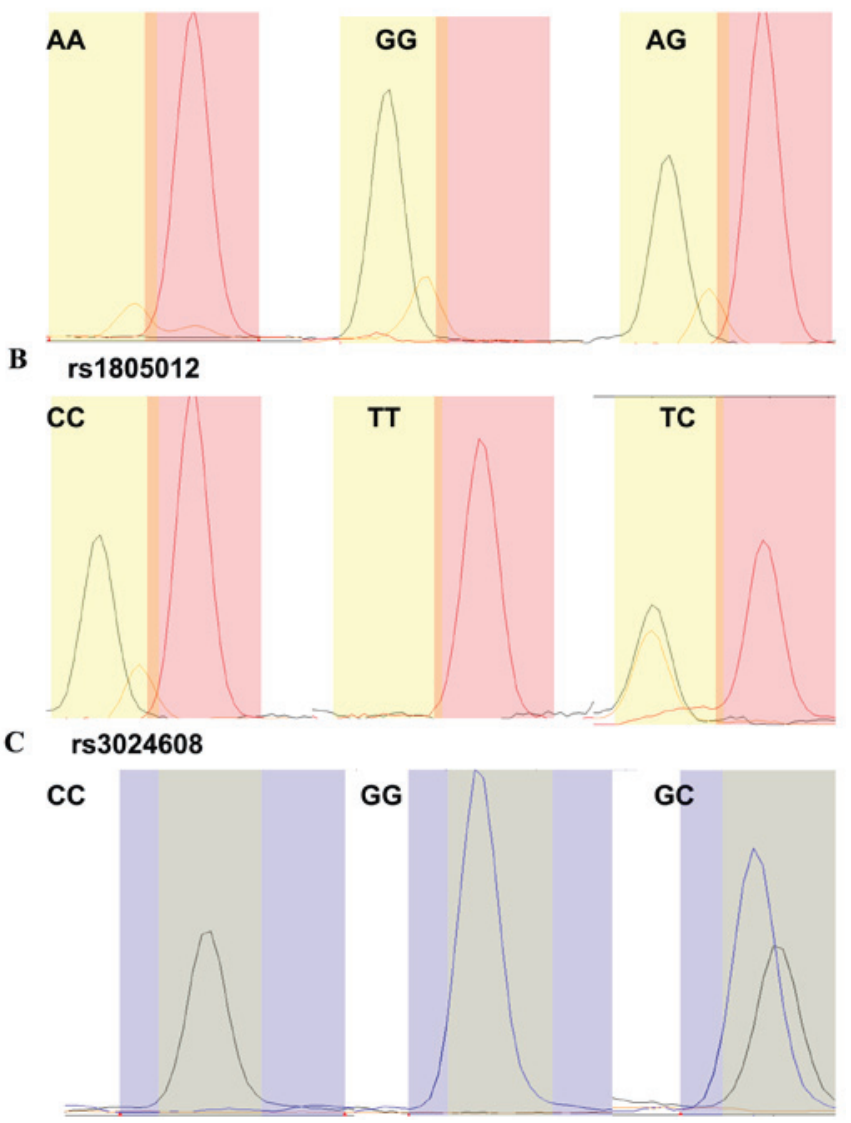

Figure 1. Different genotypes of rs1805010, rs1805012 and rs3024608. (A) AA, GG and AG genotypes of rs1805010; (B) CC, TT and TC genotypes of rs1805012; (C) CC, GG and GC genotypes of rs3024608.

gender and ethnic differences. A distinctive palm pattern was identified in asthma patients using theories of Chinese Traditional Medicine (5). However, it is difficult to confirm the clinical significance of these dermatoglyph changes in clinical practice.

As asthma is a disorder associated with multiple genetic factors, establishing the gene polymorphisms associated with asthma is considered to be a convictive method to elucidate 
the implications of the association between a distinctive palm pattern and asthma. In our previous study, two SNPs of ADAM33, rs44707 and rs2787094, were identified to be associated with a positive palm pattern (6). In the current study, of 11 analyzed SNPs of IL-4R, two SNPs were found to be associated with the distinctive palm pattern in different models (rs1805010: Log-additive model, $\mathrm{P}=0.031$; rs3024608: Codominant model, $\mathrm{P}=0.016$ ). Notably, rs3024608 was associated with the positive palm pattern and asthma in the same population; thus, IL-4R polymorphisms may be the genetic basis of the association of the distinctive palm pattern and asthma.

Recently Chavarri-Guerra and Soto-Perez-de-Celis (14) described a 65-year-old woman with stage IV breast cancer, who lost her fingerprints following chemotherapy with capecitabine and bevacizumab (18). This indicated that dermatoglyphs may change as a condition of the disease $(19,20)$. The clinical significance of dermatoglyphs requires further clarification using well-designed studies.

In conclusion, the genetic variation in IL-4R may be the basis of the association between asthma and a distinctive palm pattern. Considering the genetic variant, further studies with a prospective design in an unselected population are required to validate the association between a distinctive palm pattern and asthma, in order that a distinctive palm pattern may be considered as a biomarker for asthma development or phenotypes (21).

\section{Acknowledgements}

The authors would like to thank all participants of the study, and the Center for Human Genetics Research, Shanghai Genesky Bio-Tech Co., Ltd. for performing the SNP analysis. The current study was supported by a research grant from the National Natural Science Foundation of China (grant nos. 30873315 and 81400024).

\section{References}

1. Global Initiative for Asthma: Global Strategy for Asthma Management and Prevention. http://www.ginasthma.org.

2. Zhu J: Thelper 2 (Th2) cell differentiation, type 2 innate lymphoid cell (ILC2) development and regulation of interleukin-4 (IL-4) and IL-13 production. Cytokine 75: 14-24, 2015.

3. Zhu N, Gong Y, Chen XD, Zhang J, Long F, He J, Xia JW and Dong L: Association between the polymorphisms of interleukin-4, the interleukin-4 receptor gene and asthma. Chin Med J (Engl) 126: 2943-2951, 2013.

4. Soto-Ramírez N, Arshad SH, Holloway JW, Zhang H, Schauberger E, Ewart S, Patil V and Karmaus W: The interaction of genetic variants and DNA methylation of the interleukin-4 receptor gene increase the risk of asthma at age 18 years. Clin Epigenetics 5: 1-5, 2013.

5. Zhou ZS, Ji ZQ, Zhu XJ, Wang YQ, Xue WL, Jiang HY and Liang WH: Study on objective and quantitative atopy of thenar eminence print and its correlation with asthma. Shanghai Journal of Traditional Chinese Medicine 48: 14-15, 2014 (In Chinese).

6. Mahajan AA, Gour KK and Thakare AE: The dermatoglyphic patterns in patients of bronchial asthma - a qualitative study. Int J Biol Med Res 2: 806-807, 2011.
7. Pakhale SV, Borole BS, Doshi MA and More VP: Study of the fingertip pattern as a tool for the identification of the dermatoglyphic trait in bronchial asthma. J Clin Diagn Res 6: 1397-1400, 2012.

8. Singh S, Khurana AK, Harode HA, Tripathi A, Pakhare A and Chaware P: Study of fingerprint patterns to evaluate the role of dermatoglyphics in early detection of bronchial asthma. J Nat Sci Biol Med 7: 43-46, 2016.

9. Xue W, Han W and Zhou ZS: ADAM33 polymorphisms are associated with asthma and a distinctive palm dermatoglyphic pattern. Mol Med Rep 8: 1795-1800, 2013.

10. Cazzoletti L, Marcon A, Corsico A, Janson C, Jarvis D, Pin I, Accordini S, Bugiani M, Cerveri I, Gislason D, et al; Therapy and Health Economics Group of the European Community Respiratory Health Survey: Asthma severity according to Global Initiative for Asthma and its determinants: An international study. Int Arch Allergy Immunol 151: 70-79, 2010.

11. Wenzel SE, Balzar S, Ampleford E, Hawkins GA, Busse WW, Calhoun WJ, Castro M, Chung KF, Erzurum S, Gaston B, et al: IL4R alpha mutations are associated with asthma exacerbations and mast cell/IgE expression. Am J Respir Crit Care Med 175: 570-576, 2007.

12. Narożna B, Hoffmann A, Sobkowiak P, Schoneich N, Bręborowicz A and Szczepankiewicz A: Polymorphisms in the interleukin 4, interleukin 4 receptor and interleukin 13 genes and allergic phenotype: A case control study. Adv Med Sci 61: 40-45, 2016.

13. Murk W, Walsh K, Hsu LI, Zhao L, Bracken MB and Dewan AT: Attempted replication of 50 reported asthma risk genes identifies a SNP in RAD50 as associated with childhood atopic asthma. Hum Hered 71: 97-105, 2011.

14. Chavarri-Guerra Y and Soto-Perez-de-Celis E: Images in clinical medicine. Loss of fingerprints. N Engl J Med 372: e22, 2015.

15. Kolgeci S, Kolgeci J, Azemi M, Daka A, Shala-Beqiraj R, Kurtishi I and Sopjani M: Dermatoglyphics and Reproductive Risk in a Family with Robertsonian Translocation 14q;21q. Acta Inform Med 23: 178-183, 2015.

16. Zvi Shamir E, Levy A, Morris Cassan S, Lifshitz T, Shefler G and Tarrasch R: Do biometric parameters of the hand differentiate schizophrenia from other psychiatric disorders? A comparative evaluation using three mental health modules. Psychiatry Res 228: 425-430, 2015.

17. Ezzati A, Batoei F, Jafari SA, Kiyani MA, Mahdavi-Shahri N, Ahanchian H, Tehranian S and Kianifar HR: Dermatoglyphic patterns in cystic fibrosis children. Iran J Pediatr 24: 609-616, 2014.

18. Sen J, Kanchan T and Mondal N: A comparison of palmar dermatoglyphics in two ethnic Indian populations of north Bengal, India. J Forensic Sci 56: 109-117, 2011

19. Navit S, Chadha D, Khan SA, Singh RK, Johri N, Navit P, Sharma A and Bahuguna R: The mystery of handprints: Assesment and correlation of dermatoglyphics with early childhood caries a case-control study. J Clin Diagn Res 9: ZC44-ZC48, 2015.

20. Eslami N, Jahanbin A, Ezzati A, Banihashemi E and Kianifar H: Can dermatoglyphics be used as a marker for predicting future malocclusions? Electron Physician 8: 1927-1932, 2016.

21. Kumasaka N, Yamaguchi-Kabata Y, Takahashi A, Kubo M, Nakamura Y and Kamatani N: Establishment of a standardized system to perform population structure analyses with limited sample size or with different sets of SNP genotypes. J Hum Genet 55: 525-533, 2010. 